\title{
Histoplasma capsulatum en glándula adrenal de comadreja overa (Didelphys albiventris)
}

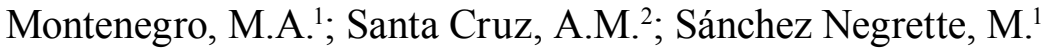 \\ ${ }^{1}$ Cátedra Patología General y Sistemática, ${ }^{2}$ Departamento de Producción Animal, Facultad de Ciencias \\ Veterinarias, UNNE, Sargento Cabral 2139, Corrientes (3400), Argentina. E-mail: patgral@vet.unne.edu.ar.
}

\begin{abstract}
Resumen
Montenegro, M.A.; Santa Cruz, A.M.; Sánchez Negrette, M.: Histoplasma capsulatum en glándula adrenal de comadreja overa (Didelphys albiventris). Rev. vet. 20: 1, 54-56, 2009. La histoplasmosis es una micosis sistémica causada por Histoplasma capsulatum que afecta principalmente los pulmones y órganos del sistema retículo endotelial y, en menor grado, glándula adrenal, hígado, sistema nervioso central y huesos. Su distribución geográfica es mundial. Afecta al hombre, perro, gato, cerdo, bovinos, equinos y animales silvestres. El objetivo del presente trabajo es comunicar los resultados del estudio anatomohistopatológico de un caso de histoplasmosis en Didelphys albiventris (comadreja overa) localizada en la glándula adrenal derecha. Muestras de todos los órganos fueron fijadas en formol al 10\%, procesadas mediante la técnica clásica para bloques parafinados, cortadas en micrótomo a $5 \mu \mathrm{m}$ y coloreadas con hematoxilina-eosina, PAS, Giemsa y Groccot. Histoplasma capsulatum fue identificado histológicamente en el interior de los macrófagos y en los espacios intersticiales. El hallazgo de este hongo en la comadreja overa, un animal que habita zonas periurbanas de Corrientes, Argentina, constituye un llamado de atención ya que sería un agente infeccioso más para esta especie, pudiendo actuar como reservorio.
\end{abstract}

Palabras clave: Didelphys albiventris, histoplasmosis, glándula adrenal.

\begin{abstract}
Montenegro, M.A.; Santa Cruz, A.M.; Sánchez Negrette, M.: Histoplasma capsulatum in adrenal gland in comadreja overa (Didelphys albiventris). Rev. vet. 20: 1, 54-56, 2009. Histoplasmosis is a systemic mycosis caused by Histoplasma capsulatum. The most affected organs are lungs, reticuloendothelial system, and rarely adrenal glands, liver, central nervous system and bones. Its distribution is worldwide. The disease occurs in human beings, dog, cat, pig, cattle, horse, and wild animals. The objective of this work is to report the results of the anatomohistopathological study of a case of adrenal gland histoplasmosis in Didelphys albiventris. Samples from all organs were fixed in $10 \%$ buffered formaldehyde and, following the classic technique, sections were embedded in paraffin, sliced in $5 \mu \mathrm{m}$ and finally stained with hematoxiline-eosine, PAS, Giemsa and Groccot. Histoplasma capsulatum was identified inside macrophages and interstitial space. The finding of this mycosis in D. albiventris, a wild animal that lives in suburban areas of Corrientes, Argentina, should make consider this species as a potential reservoir of the disease.
\end{abstract}

Key words: Didelphys albiventris, histoplasmosis, adrenal gland.

\section{INTRODUCCIÓN}

La histoplasmosis es una micosis sistémica causada por Histoplasma capsulatum. Su distribución es mundial, habiendo sido reportada en más de 40 países $3,9,10,13$. Se han registrado altos índices de infección en México, Venezuela, Uruguay, Brasil, países de Centroamérica, Europa y en menor proporción Asia y Sudáfrica ${ }^{12-14}$. En Estados Unidos existen áreas endémicas,

Recibido: 8 diciembre 2008 / Aceptado: 6 abril 2009 siendo las más afectadas el este y centro del país ${ }^{3}$. En Argentina las zonas de mayor incidencia son las provincias de Buenos Aires, Santa Fe, Córdoba y Tucumán ${ }^{6}$.

El suelo y el aire constituyen el hábitat natural del hongo, que abunda especialmente en lugares enriquecidos con heces de animales domésticos y silvestres, como aves y murciélagos, existiendo una asociación característica entre infección por $H$. capsulatum y lugares donde se congregan palomas, así como en gallineros y casas abandonadas ${ }^{3,9}$. La enfermedad se adquiere por inhalación de partículas de polvo procedente de suelos 
contaminados por excrementos de pájaros o murciélagos, las cuales contienen las esporas (microconidias), que constituyen la forma infectante del hongo ${ }^{1}$. Afecta principalmente a los pulmones y a los órganos del sistema retículoendotelial, en menor grado a la glándula adrenal, sistema nervioso central y huesos. La vía de entrada más común es la inhalatoria, pudiendo excepcionalmente ingresar por mucosas o piel ${ }^{4}$.

La inhalación de esporas o hifas causa una infección pulmonar primaria, la cual puede ser transitoria o progresar para formar una o varias lesiones crónicas bien circunscriptas (histoplasmonas) ${ }^{2,7}$. Cuando la diseminación se produce por vía sanguínea pueden formarse lesiones focales no progresivas en otros órganos ${ }^{3}$. En pacientes resistentes, H. capsulatum provoca una reacción granulomatosa en células epiteliales, que recuerda a la tuberculosis, siendo la calcificación un rasgo característico de las lesiones necróticas antiguas ${ }^{5}$. En su fase parasitaria, el agente etiológico es fácilmente demostrable dentro de macrófagos con la coloración hematoxilina-eosina, como elementos circulares intracelulares de 3 a $5 \mu \mathrm{m}$ de diámetro, presentando una rígida pared celular ${ }^{11,12}$. Afecta al hombre, perro, gato, cerdo, equino y animales salvajes, no existiendo evidencia de transmisión de hombre a hombre o de animal al hombre ${ }^{8,10}$.

El objetivo del presente trabajo es reportar los resultados del estudio anatomohistopatológico de un caso de histoplasmosis en la glándula adrenal de Didelphys albiventris (comadreja overa).

\section{MATERIAL Y MÉTODOS}

Luego de realizada la necropsia a una comadreja overa, adulta y de sexo hembra, todos los órganos fueron fijados en formol al $10 \%$, procesados por la técnica clásica para bloques parafinados, cortados en $5 \mu \mathrm{m}$ y coloreados con hematoxilina-eosina (HyE), Giemsa, PAS y Grocott.

\section{RESULTADOS Y DISCUSIÓN}

Durante el examen postmortem se encontró la glándula adrenal derecha aumentada de tamaño, de color blanquecino-amarillento, consistencia firme-elástica y al corte pérdida de las estructuras cortical y medular, presentando en su lugar un tejido blanquecino de aspecto cremoso.

El estudio histopatológico de la glándula adrenal afectada, permitió detectar extensas zonas de necrosis, conformando estructuras de tipo granulomatosas con áreas de microcalcificación, similares a lesiones de tuberculosis. La zona glomerular se hallaba parcialmente conservada, la zona fascicular presentaba intenso infiltrado linfoplasmocitario, en tanto que la zona reticular fue el área más afectada, observándose un gran número de macrófagos y células epitelioides dispuestas en empalizada rodeando al tejido necrótico (Figura 1).
H. capsulatum fue identificado con la coloración de rutina (HyE) en el interior de los macrófagos (Figura 2), así como en el espacio intersticial, principalmente de la zona reticular de la corteza. Dicho microorganismo se presentó como múltiples estructuras circulares, de aproximadamente $3 \mu \mathrm{m}$ de diámetro, conformadas por una rígida pared celular y un espacio claro producto de la retracción del protoplasma que se produce durante la fijación y que brinda la impresión errónea de una cápsula sin colorear.

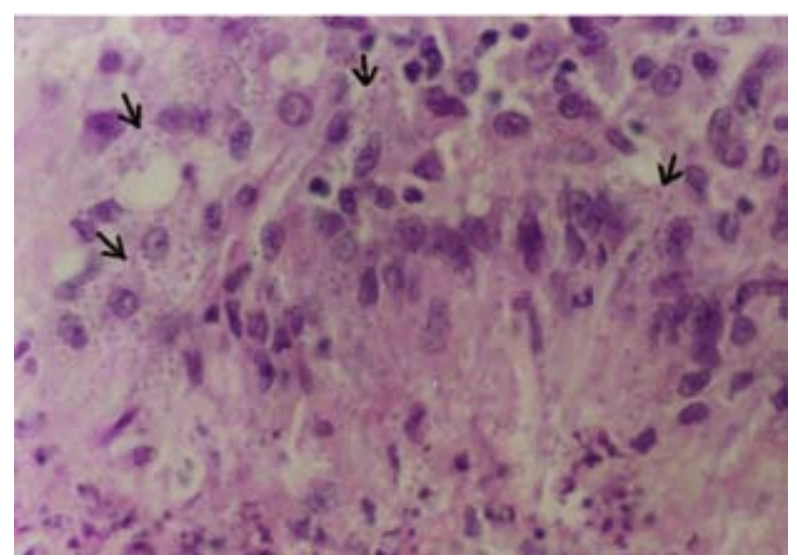

Figura 1. Granuloma con centro necrótico y células epitelioides dispuestas en empalizada con histoplasmas (flechas) en su interior (HyE 400x).

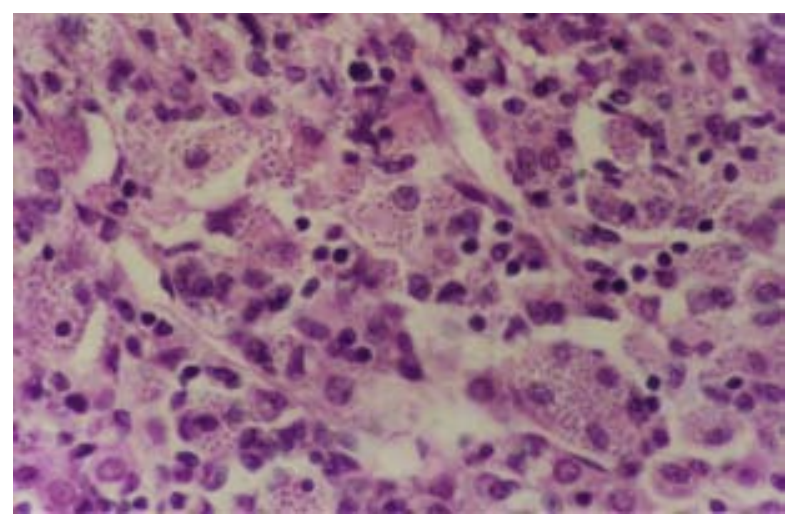

Figura 2. Periferia del granuloma mostrando en detalle numerosos histoplasmas dentro de los macrófagos (HyE 400x).

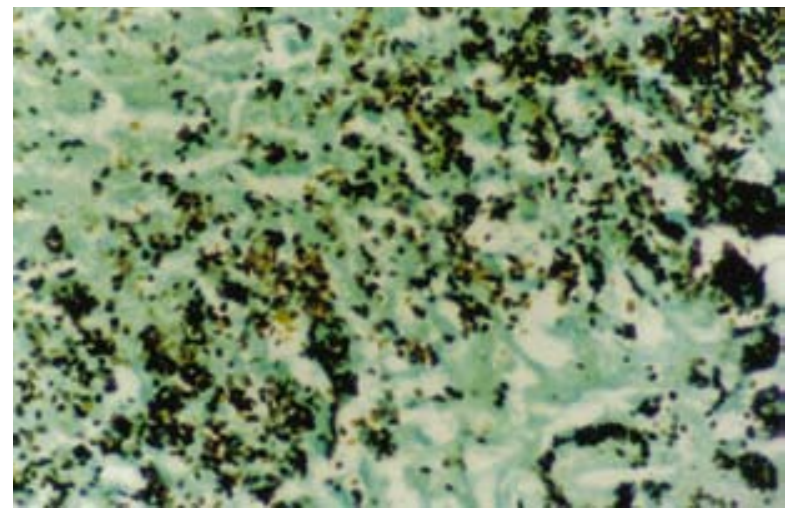

Figura 3. Periferia de tejido necrótico con abundantes histoplasmas coloreados de negro y marrón oscuro con la técnica especial para hongos (Grocott 400x). 
Con las coloraciones especiales para hongos tales como Grocott y PAS, H. capsulatum fue claramente evidenciado (Figura 3). El estudio de los pulmones, corazón, encéfalo, hígado, tracto gastrointestinal y riñones no mostró lesiones macroscópicas ni microscópicas compatibles con la presencia del hongo.

El presente caso tipificó como una presentación de tipo granulomatosa localizada en la glándula adrenal, con intenso depósito de calcio característico de los procesos crónicos. Si bien no existen evidencias de transmisión del animal al hombre ${ }^{8,10}$, el hallazgo de $H$. capsulatum en la comadreja overa constituye un llamado de atención tendiente a poner en alerta los controles epidemiológicos por su posible propagación y fuente de contagio al ser humano.

\section{REFERENCIAS}

1 Acha PN, Szyfres B. 1977. Zoonosis y enfermedades transmisibles comunes al hombre y a los animales, Ed. OPSOMS, Washington (USA), p. 156-159.

2. Berry CL. 1969. The development of the granuloma of histoplasmosis. J Pathol 97: 1-10.

3. Binford CH, Connor DH. 1976. Pathology of tropical and extraordinary diseases, Publ. Armed Forces Institute of Pathology, Washington (USA), p. 576-578.

4. Cotran RS, Kumar V, Collins T. 2000. Robbins: Patología estructural y funcional, $6^{\circ}$ ed., McGraw-Hill, Madrid, p. 373-374.
5. Dade AW, Lickfeldt WE, McAllister HA. 1973. Granulomatous colitis in a horse with histoplasmosis. Vet Med Small Anim Clin 68: 279-281.

6. Elsner B, Iotti R, Parisi C, Caputi E. 1979. Lecciones de patología, López Libreros, Buenos Aires, p. 199-200.

7. Farell RL, Cole CR. 1968. Experimental canine histoplasmosis with acute fatal and chronic recovered courses. Am J. Pathol 53: 425-445.

8. Hoff B, Fogle B. 1970. Histoplasmosis in a dog. Can Vet J 11: $145-148$.

9. Jubb KV, Kennedy PC, Palmer N. 2007. Pathology of domestic animals, $5^{\circ}$ ed., Saunders, Philadelphia (USA), p. 300-304.

10. Mahaffey E. 1977. Disseminated histoplasmosis in three cats. J Am Anim Hosp Assoc 13: 46-51.

11. Maresca B. 1994. Morphological transition in the human fungal pathogen Histoplasma capsulatum. Trends Microbiol 2: 110-112.

12. Menges, RW, Furcolow, ML, Huberman RT. 1954. An outbreak of histoplasmosis involving animals and man. Am J Vet Res 15: 520-524.

13. McGavin DM, Zachary JF. 2007. Pathologic basis of veterinary disease, $4^{\circ}$ ed., Mosby, St. Louis (USA), p. 714.

14. Wu-Hsieh BA. 1992. Early activation of splenic macrophages by tumour necrosis factor alpha is important in determining the outcome of experimental histoplasmosis in mice. Infect Immun 60: 4230-4238. 